Article

\title{
Two-Sided Surface Oxidized Cellulose Membranes Modified with PEI: Preparation, Characterization and Application for Dyes Removal
}

\author{
Wei Wang *, Qian Bai, Tao Liang, Huiyu Bai and Xiaoya Liu \\ Key Laboratory of Synthetic and Biological Colloids, Ministry of Education, School of Chemical and \\ Material Engineering, Jiangnan University, Wuxi 214122, China; qianbaichem@163.com (Q.B.); \\ taoliangchem@163.com (T.L.); bhy.chem@163.com (H.B.); lxy@jiangnan.edu.cn (X.L.) \\ * Correspondence: ww12230098@sina.com or weiwangpolymer@163.com
}

Received: 16 August 2017; Accepted: 13 September 2017; Published: 16 September 2017

\begin{abstract}
Porous regenerated cellulose (RC) membranes were prepared with cotton linter pulp as a raw material. These membranes were first oxidized on both sides by a modified (2,2,6,6-tetramethylpiperidin-1-yl)oxyl (TEMPO) oxidation system using a controlled oxidation reaction technique. Then, the oxidized $\mathrm{RC}$ membranes were functionalized with polyethylenimine (PEI) via the glutaraldehyde crosslinking method to obtain bifunctional (carboxyl and amino) porous RC membranes, as revealed by Fourier transform infrared spectroscopy (FT-IR), elemental analysis and zeta potential measurement. The scanning electron microscopy (SEM) and the tests of the mechanical properties and permeability characteristics of modified RC membranes demonstrated that the porous structure and certain mechanical properties could be retained. The adsorption performance of the modified membranes towards dyes was subsequently investigated. The modified membranes displayed good adsorption capacities, rapid adsorption equilibrium and removal efficiencies towards both anionic (xylenol orange $(\mathrm{XO})$ ) and cationic (methylene blue $(\mathrm{MB})$ ) dyes, making them suitable bioadsorbents for wastewater treatment.
\end{abstract}

Keywords: regenerated celluloses; bioadsorbents; dye removal; functional membranes

\section{Introduction}

Synthetic dyes are widely utilized in numerous industries (e.g., textile, paper, leather tanning, plastics, rubber, cosmetics and printing) owing to their high stability, relatively low costs and color uniformity characteristics [1,2]. Inevitably, a certain fraction of dyes end up in the effluent during the dyeing process. This colored waste water must be purified before being released into the environment since it is toxic, carcinogen and can damage the aquatic ecological balance [3]. Various methods (e.g., adsorption, membrane separation, chemical oxidation, coagulation-flocculation, photochemical degradation and bioremoval) have been used singly or in combination with other approaches for the removal of dyes [4-6]. Among them, adsorption is considered to be economically and environmentally superior to other conventional techniques owing to its easy operation, low cost and effectiveness [7]. However, mechanical agitation is often required to improve the adsorption efficiency by enhancing the contact between the dyes and the adsorbents. Moreover, numerous adsorbents usually require long times before reaching adsorption equilibrium [8].

One paradigmatic adsorbent for the removal of a target pollutant should exhibit a large surface area, good adsorption efficiency and an abundance of adsorption sites while being produced at low cost and in a sustainable and environmentally-friendly manner. Sharma et al. compiled a list of naturally available, low cost and eco-friendly adsorbents for the removal of hazardous dyes from aqueous 
waste streams via adsorption [4]. Various methods including carbonization, chemical activation and pyrolysis have been proposed to enhance the adsorption efficiency for dyes [9].

Biodegradable and biocompatible cellulose-based materials have been developed in recent decades taking advantage of the wide availability (i.e., the most abundant renewable biopolymer in nature) and low cost characteristics of this polymer. These materials have been used for water treatment purposes especially, as a new class of versatile adsorbents for the removal of dyes. Moreover, the high density of surface hydroxyl groups present on cellulose provides this material with excellent surface modification characteristics, thereby allowing a wide range of functionalization approaches for the adsorption of dyes from aqueous solutions [10]. Thus, different forms of cellulose-based materials have been used as dye adsorbents. Jin et al. prepared amino-functionalized nanocrystalline cellulose, and the sample was then applied as an adsorbent to remove anionic dyes in aqueous solutions [11]. A carboxylate-functionalized adsorbent based on CNCs was prepared, and adsorptive removal of multiple cationic dyes was investigated [12]. Cellulose recycled newspaper fibers were grafted with double quaternary ammonium groups, and the maximum adsorption capacity of this for RTB G-133 was $524 \mathrm{mg} \cdot \mathrm{g}^{-1}$ [13]. Luo et al. developed millimeter-scale magnetic regenerated cellulose (RC) beads, and the adsorbent could efficiently adsorb the organic dyes from wastewater, as well as the used adsorbents could be recovered completely [14]. Cellulose nanosponges modified with methyltrioctylammonium chloride were prepared and used for pre-concentration, removal and determination of tartrazine dye, using UV-Vis spectrophotometry [15]. Cellulose powders functionalized with hyperbranched polyethylenimine were prepared, and used for selective dye adsorption and separation based on the unique selective adsorption [16].

Cellulose membranes can be also used as dye adsorbents, benefitting from the porous structure, the adsorption capacity for the removal of positively-charged dyes and good reusable performance, however in the form of multilayer [17], composites [18,19] and cellulose derivatives [20]. However, at present, many studies have focused on using membrane separation technology as the cellulose-based membranes are used for water treatment [21,22], and there are less reports on the pure cellulose functional membranes as adsorbents. Oshima et al., reported phosphorylated bacterial cellulose as an adsorbent for metal Ions [23]. As described above, when used as adsorbents, celluloses need to undergo chemical modification for achieving efficient adsorption. However, during the modification process, celluloses are often subjected to strong acid or oxidant, etc., treatments, so leading to the degradation of cellulose macromolecules [24], which further may damage the porous structures of the cellulose membranes and even destroy membranes themselves. These facts can significantly limit the application of cellulose membranes for adsorption purposes.

In this study, cotton linter pulp was used as a raw material to prepare porous RC membranes by using a phase-inversion method. Subsequently, the RC membranes underwent a two-sided surface oxidation treatment with a modified (2,2,6,6-tetramethylpiperidin-1-yl)oxyl (TEMPO) oxidation system to yield the corresponding C-6 carboxyl membrane materials. To prevent the cellulose membranes from being damaged via oxidation-degradation of the cellulose macromolecular chains, a control oxidation reaction was carried out by following the method described by Fitz-Binder et al. [25]. Amine groups were subsequently incorporated onto the oxidized cellulose membranes by grafting polyethylenimine (PEI) via the glutaraldehyde crosslinking method [26]. As a result, porous RC membranes containing both carboxyl and amino groups were obtained. Fourier transform infrared spectroscopy (FT-IR), elemental analysis and zeta potential measurement and scanning electron microscopy (SEM) were used to analyze the structure and morphology of the modified cellulose membranes. Furthermore, anionic and cationic dyes were both used as model pollutants to evaluate the dye removal efficiency of the modified cellulose membranes. The adsorption performance and kinetic behaviors during dye adsorption on the cellulose-based adsorbents were further investigated. With the aim to further evaluate the potential application of the modified RC membranes for water treatment purposes, the porosity, pure water permeability characteristics and the mechanical properties of the modified RC membranes were also tested. 


\section{Experimental Section}

\subsection{Materials}

Cellulose (cotton linter pulp, $\alpha$-cellulose $\geq 95 \%$ ) was purchased from Hubei Chemical Fiber Group Ltd. (Xiangfan, China). PEI (molecular weight of $600 \mathrm{Da}$ ), TEMPO (AR), xylenol orange (XO) (AR) and methylene blue (MB) (AR) were supplied by Aladdin Chemical Reagent Corp., Shanghai, China. Other reagents used in this work were of analytical grade and purchased from Sinopharm Chemical Reagent Co., Shanghai, China.

\subsection{Preparation of the $R C$ Membranes}

RC membranes were prepared according to a reported method [27]. Five grams of cotton linter pulp were added to a $\mathrm{LiOH} /$ urea $/ \mathrm{H}_{2} \mathrm{O}(8.76 / 12 / 79.24$ in wt $\%, 100 \mathrm{~g})$ solution, and the resulting aqueous solution was stored at $200{ }^{\circ} \mathrm{C}$ for $20 \mathrm{~h}$. The frozen cellulose solution was then vigorously stirred for $5 \mathrm{~min}$ at ambient temperature to obtain a transparent cellulose dope. The cellulose dope was then subjected to centrifugation at $8000 \mathrm{rpm}$ for $10 \mathrm{~min}$ at $-4{ }^{\circ} \mathrm{C}$, and the transparent supernatant fraction was immediately cast on a glass plate. Subsequently, the resulting gel sheets were coagulated with a sulfate aqueous solution to obtain a transparent membrane. The wet membrane was washed with deionized water and dried at ambient temperature to finally obtain the RC membrane.

\subsection{Preparation of the TEMPO-Oxidized RC Membranes}

Oxidized cellulose membranes were prepared according to a reported method [25]. First, the RC membrane was immersed in $1 \mathrm{~L}$ of a boric acid $(0.1 \mathrm{M})$ buffer solution $(\mathrm{pH}=10.5)$, and $2 \mathrm{~g}$ of $\mathrm{NaBr}$ and $0.3 \mathrm{~g}$ of TEMPO were subsequently added and mixed by magnetic stirring for $180 \mathrm{~min}$. The pre-wetted membranes were then dried at $60^{\circ} \mathrm{C}$ for $5 \mathrm{~min}$. For the printing paste, $5 \mathrm{~g}$ of alginate were dissolved in $40 \mathrm{~mL}$ of the boric acid buffer solution to form a thickener, and $6 \mathrm{~mL}$ of $\mathrm{NaOCl}$ were added to the former paste. The mixtures were then stirred to obtain a homogenous paste. Subsequently, the as-prepared thickener paste was applied by printing it on the one-sided surface of the RC membranes containing the $\mathrm{NaBr} / \mathrm{TEMPO} /$ buffer mixture, and the prints were rested for $60 \mathrm{~min}$. Finally, the printing membrane was thoroughly washed with water. The other side of the cellulose membrane was impregnated in a similar way to generate the two-sided surface TEMPO-oxidized regenerated cellulose (TORC) membrane.

\subsection{Preparation of Aminated TORC Membranes}

The oxidized RC membranes were cut into approximately $80 \mathrm{~mm} \times 70 \mathrm{~mm} \times 0.1 \mathrm{~mm}$ pieces and saturated in $50 \mathrm{~mL}$ of an anhydrous methanol solution. Four grams of PEI were added, and the resulting solution was stirred at room temperature for $24 \mathrm{~h}$. After that, the wet membranes were rinsed with water to remove the residual PEI and immediately immersed in $100 \mathrm{~mL}$ of an anhydrous methanol solution. Subsequently, $20 \mathrm{~mL}$ of a glutaraldehyde solution were added dropwise, and the resultant mixtures were stirred at $25^{\circ} \mathrm{C}$ for $2 \mathrm{~h}$. Finally, the modified cellulose membranes were repeatedly washed with deionized water to remove the unreacted material and denoted as PEI-TORC membranes.

\subsection{Characterization of the Functionalized TORC Membranes}

The RC and modified RC membranes were chemically characterized by attenuated total reflectance infrared (ATR-IR) spectroscopy (Nicolet 560, Nicolet Co., Ltd., Madison, WI, USA). The spectra were recorded from $600-4000 \mathrm{~cm}^{-1}$ with a resolution of $2 \mathrm{~cm}^{-1}$ and a minimum of 16 scans. The mass ratios of $\mathrm{C}, \mathrm{H}, \mathrm{O}$ and $\mathrm{N}$ of each sample were measured using Elemental Analyzer (Vario EL III, Elementar Co., Langenselbold, Germany). The surface and cross-section morphologies of the RC and modified RC membranes were assessed by using a scanning electron microscope (S-4800, Hitachi Corporation, Tokyo, Japan). Cross-sectional faces of membranes were prepared by being fractured in liquid nitrogen. 
The samples were deposited on a glass plate and coated with a thin layer of gold/palladium using a sputter coater (K550X, Emitech Ltd., Kent, UK). The pore size analysis of the membrane surface was calculated by using the software of SEM image analysis (Nano Measurer System, Version 1.2.5, Fudan University, Shanghai, China). The surface charge of the PEI-TORC membrane was determined by zeta-potential measurement using an Electrokinetic Analyzer (SurPASS, Anton Paar, Graz, Austria), using a $2 \mathrm{mM} \mathrm{KCl}$ electrolyte solution. The tensile strength and strain at break of the membranes were measured on a universal testing machine (Instron 5967, Instron, Norwood, MA, USA), using a 250-N load cell at room temperature. The strain rate was set at $10 \mathrm{~mm} / \mathrm{min}$, and five measurements were taken for each sample.

The porosities of the modified membranes were calculated using a reported method [22]. The porosity $(P)$ was calculated as Equation (1):

$$
P=\frac{\left(M_{1}-M_{2}\right) / q_{1}}{\left(M_{1}-M_{2}\right) / q_{1}+M_{2} / q_{2}} \times 100 \%
$$

The wet membranes were weighed as $M_{1}$ and then freeze dried overnight and weighed as $M_{2}$. The water content was calculated as $M_{1}-M_{2} . q_{1}$ is water density, and $q_{2}$ is PEI-TORC density (calculated according to the density of bulk cellulose, $1.5 \mathrm{~g} \mathrm{~cm}^{-3}$ ).

The water flux of the modified membranes was evaluated using a reported method [28]. The pure water permeability test of the wet membranes was carried out on miniature microfiltration equipment at ambient temperature under an operation pressure of $0.1 \mathrm{MPa}$, while the water flux was calculated according to Equation (2):

$$
J_{w}=\frac{V}{S \times t \times P}
$$

where $V$ is the volume of solvent passing through the membrane; $t$ is the measurement time; $S$ is the effective membrane area; $P$ is the pressure $(0.1 \mathrm{MPa})$.

The mean pore radius, $r_{\mathrm{f}}$, was calculated by employing Equation (3), derived based on the straight-through cylindrical pore model [29].

$$
\eta=\sqrt{\frac{8 \times \eta \times I \times J}{P \times \Delta P}}
$$

where $\eta$ is the water viscosity $\left(8.9 \times 10^{-4} \mathrm{~Pa} \mathrm{~s}\right), I$ is the membrane thickness $(\mathrm{m}), J$ is the permeation flux $\left(\mathrm{m}^{3} \cdot \mathrm{m}^{-2} \cdot \mathrm{s}^{-1}\right)$ and $\Delta P$ is the load pressure $(\mathrm{Pa})$.

\subsection{Batch Adsorption Experiments}

Batch adsorption experiments were conducted in some $100 \mathrm{~mL}$ glass conical flasks in a water bath shaker $\left(25^{\circ} \mathrm{C}, 200 \mathrm{rpm}\right)$. Each flask contained $60 \mathrm{~mL} \mathrm{MB}$ or XO solution and $70 \mathrm{mg}$ adsorbent. The $\mathrm{pH}$ of the solution was adjusted by adding $0.1 \mathrm{M} \mathrm{HCl}$ or $\mathrm{NaOH}$ aqueous solutions. At predetermined time intervals, approximately $3 \mathrm{~mL}$ of dye solution were used for UV-Vis measurements and afterwards returned into the flask. This was repeated until equilibrium was reached. The dye removal efficiencies of the RC and PEI-TORC membranes towards $\mathrm{XO}$ and $\mathrm{MB}$ were investigated for $100 \mathrm{~min}$ (dye concentration, $30 \mathrm{mg} \cdot \mathrm{L}^{-1}, \mathrm{pH}=6.8$ ). The effect of $\mathrm{pH}$ on the removal efficiency was investigated in the range of 4-11 for $100 \mathrm{~min}$ (dye concentration: $30 \mathrm{mg} \cdot \mathrm{L}^{-1}$ ). The effect of initial dye concentration on the adsorption performance was investigated in the range from $30-1230 \mathrm{mg} \cdot \mathrm{L}^{-1}$ (at pH values of 6.8 and 4.6) for $120 \mathrm{~min}$. The effect of the contact time (10-100 $\mathrm{min}$ ) was investigated (dye concentration, $30 \mathrm{mg} \cdot \mathrm{L}^{-1}$ ) at $\mathrm{pH} 6.8$ and 4.6 .

The removal efficiency and adsorption capacity of dyes were calculated according to Equations (4) and (5):

$$
\text { adsorption capacity }\left(\mathrm{mg} \cdot \mathrm{g}^{-1}\right)=\frac{\left(C_{0}-C_{t}\right) \times V}{m} \times 100
$$




$$
\text { Removal efficiency }(\%)=\frac{C_{0}-C_{t}}{C_{0}} \times 100
$$

where $C_{0}\left(\mathrm{mg} \cdot \mathrm{L}^{-1}\right)$ and $C_{t}\left(\mathrm{mg} \cdot \mathrm{L}^{-1}\right)$ are the initial concentration of the dye and the concentration of the dye at an adsorption time $t$, respectively, $\mathrm{V}$ is the volume of the dye solution and $\mathrm{m}$ is the weight of the adsorbent.

The evaluation of the reusability of the adsorbent was carried out at a $0.07 \mathrm{~g} \cdot \mathrm{L}^{-1}$ dosage of bioadsorbent added into $60 \mathrm{~mL}$ of $30 \mathrm{mg} \cdot \mathrm{L}^{-1}$ dye solutions for $100 \mathrm{~min}$, and then, the adsorbent was taken out from the solution. The desorption and regeneration of the used adsorbent was performed by immersing the adsorbent in $30 \mathrm{~mL}$ of a $0.1 \mathrm{M} \mathrm{NaOH}$ or $\mathrm{HCl}$ solution for $5 \mathrm{~h}$ at room temperature and subsequently washed using distilled water till neutral for the next adsorption. The generated adsorbent was used for another adsorption study in the subsequent cycles.

\subsection{Adsorption Isotherm and Kinetic Model}

The Langmuir and Freundlich models [30] can be used to describe the adsorption dynamic equilibrium process by Equations (6) and (7):

$$
\begin{gathered}
\frac{c_{e}}{q_{e}}=\frac{1}{k_{1} q_{\max }}+\frac{c_{e}}{q_{\max }} \\
I n q_{e}=I n k_{f}+\frac{I n c_{e}}{n}
\end{gathered}
$$

where $q_{\mathrm{e}}\left(\mathrm{mg} \cdot \mathrm{g}^{-1}\right)$ is the equilibrium adsorption capacity, $q_{\mathrm{max}}\left(\mathrm{mg} \cdot \mathrm{g}^{-1}\right)$ is the maximum adsorption capacity, $C_{\mathrm{e}}\left(\mathrm{mg} \cdot \mathrm{L}^{-1}\right)$ is the equilibrium concentration of free dye molecules in the solution $\left(\mathrm{mg} \cdot \mathrm{L}^{-1}\right)$, $K_{1}$ is the Langmuir constant and $K_{\mathrm{f}}$ and $1 / n$ are Freundlich constants.

In order to explore the adsorption mechanism of the rate limiting steps involved, the pseudo-first order and the pseudo-second order kinetic models [31] were used to study the type of adsorption and the adsorption mechanism. The first and second order rate equations can be expressed as Equations (8) and (9):

$$
\begin{gathered}
\log \left(q_{e}-q_{t}\right)=\log q_{e}-\frac{k_{1} t}{2.303} \\
\frac{t}{q_{t}}=\frac{1}{k_{2} q_{e}^{2}}+\frac{t}{q_{e}}
\end{gathered}
$$

where $q_{\mathrm{e}}$ and $q_{\mathrm{t}}$ are the amounts of adsorbed dye per unit mass of adsorbent $\left(\mathrm{mg} \cdot \mathrm{g}^{-1}\right)$ at equilibrium and a time $t$, respectively, and $k_{1}$ and $k_{2}$ are the first order and the pseudo-second order adsorption rate constants, respectively.

\section{Results and Discussion}

\subsection{Characterization of the Modified RC Membranes}

The FTIR spectra of the RC, TORC and PEI-TORC membranes are shown in Figure 1a. Compared with the unmodified RC, the FTIR spectra of the TORC membranes showed a new peak at $1736 \mathrm{~cm}^{-1}$, which was attributed to the $\mathrm{C}=\mathrm{O}$ stretching frequency of the carboxyl group [32], thereby revealing a successful TEMPO-oxidation process. In the case of the PEI-TORC membranes, new absorption bands were observed at ca. $1653 \mathrm{~cm}^{-1}$ corresponding to the $\mathrm{C}=\mathrm{N}$ stretching vibration, which was formed in the glutaraldehyde crosslinking process. Three new peaks appeared in the $1600-1800-\mathrm{cm}^{-1}$ region and were ascribed to the $\mathrm{C}=\mathrm{O}$ stretching vibration of carboxyl groups $\left(1736 \mathrm{~cm}^{-1}\right)$, the $\mathrm{N}-\mathrm{H}$ bending vibration of secondary $\left(1615 \mathrm{~cm}^{-1}\right)$ and primary $\left(1564 \mathrm{~cm}^{-1}\right)$ amines $[33,34]$. Furthermore, the large enhancement of the $\mathrm{C}-\mathrm{C}$ skeleton vibration at $1157 \mathrm{~cm}^{-1}$ and the presence of the $\mathrm{C}-\mathrm{H}$ characteristic peaks at 2924 and $2849 \mathrm{~cm}^{-1}$ for the PEI-TORC membranes further demonstrated the successful crosslinking reaction. 


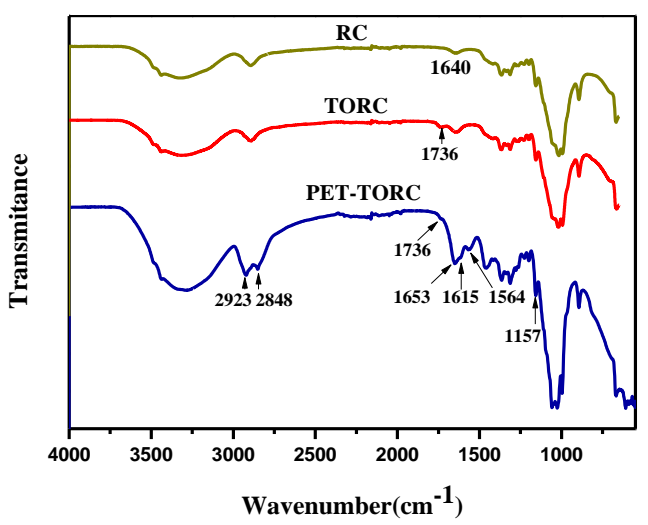

(a)

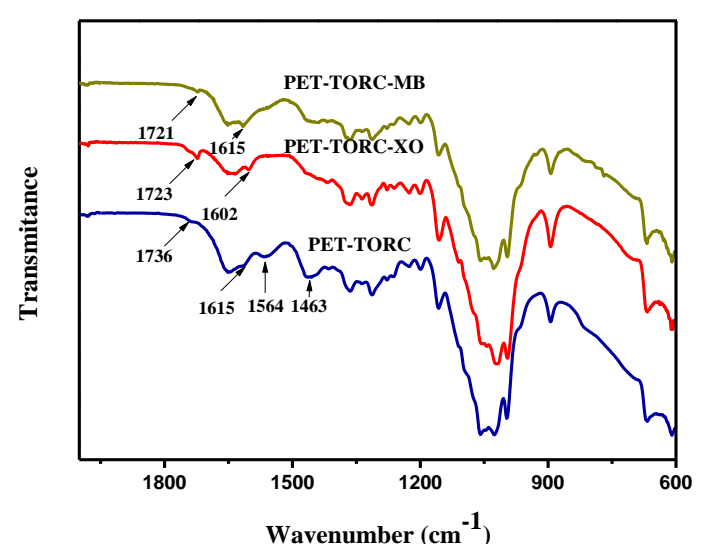

(b)

Figure 1. (a) FTIR spectra of RC, TORC, polyethylenimine(PEI)-(2,2,6,6-tetramethylpiperidin-1-yl)oxyl (TEMPO)-oxidized regenerated cellulose (TORC); (b) FTIR spectra of xylenol orange (XO)-adsorbed PEI-TORC and MB-adsorbed PEI-TORC.

In order to evaluate the change of the content of the elements in the whole material after modification, the contents of $\mathrm{C}, \mathrm{N}, \mathrm{O}$ and $\mathrm{H}$ in different cellulose-based membranes are listed in Table 1. After TEMPO oxidation, the oxygen content in cellulose increased from $49.11-51.29 \%$. The nitrogen content of PEI-TORC increased significantly from $0-3.87 \%$ compared to that of TORC. The elemental analysis data and the FTIR results both confirmed the successful oxidation of cellulose and PEI grafting on TORC.

Table 1. Elements analysis results of unmodified and modified cellulose membranes.

\begin{tabular}{ccccc}
\hline Sample & $\mathbf{C ~ ( \% )}$ & $\mathbf{O}(\mathbf{\%})$ & $\mathbf{H ~ ( \% )}$ & $\mathbf{N ~ ( \% )}$ \\
\hline RC & 41.02 & 49.11 & 9.87 & 0 \\
TORC & 39.64 & 51.29 & 9.07 & 0 \\
PEI-TORC & 41.98 & 45.91 & 8.24 & 3.87 \\
\hline
\end{tabular}

FT-IR is a useful tool to study the possible adsorbent-adsorbate interactions. The FT-IR spectra of the cellulose-based and the dye-loaded bioadsorbents are shown in Figure 1b. After dye adsorption, the adsorption peaks of the bioadsorbent shifted towards lower wavenumbers. For example, the adsorption peak attributed to the $\mathrm{C}=\mathrm{O}$ stretching vibration shifted from 1736 to $1725 \mathrm{~cm}^{-1}$ (for $\mathrm{XO}$ ) and $1724 \mathrm{~cm}^{-1}$ (for $\mathrm{MB}$ ). The absorption bands assigned to the $\mathrm{N}-\mathrm{H}$ stretching vibration shifted from 1615 to $1602 \mathrm{~cm}^{-1}$ (for XO) and $1613 \mathrm{~cm}^{-1}$ (for MB). After absorption, the disappearance of the $\mathrm{N}-\mathrm{H}$ bending vibration peak of primary amines $\left(1564 \mathrm{~cm}^{-1}\right)$ and the variation of the $\mathrm{CH}_{2}$ bending peak $\left(1463 \mathrm{~cm}^{-1}\right)$ also revealed the existence of electrostatic and hydrogen bonding interactions between the functional groups of the adsorbent and the dye molecules.

The SEM images for the RC, TORC and PEI-TORC membranes are shown in Figure 2. Surface morphology changes of cellulose-based membranes were observed; the porous structure of RC was maintained after TEMPO oxidation and crosslinking reaction. The average diameter of the pores of the pure cellulose membrane surface from SEM $(78 \mathrm{~nm}$, standard deviation of 18) was larger than that of PEI-TORC (43 nm, standard deviation of 10), revealing the reaction on the surface of the cellulose, introducing new groups and molecular chains on the membrane surface. As shown in the SEM images of the cross-section of cellulose-based membranes, compared with the cross-section morphology of RC membranes, the interior structures of TORC and PEI-TORC membranes had changed greatly. The cross-section of the RC membrane was relatively smooth. Interestingly, it can be observed that the cross-section image of the TORC membrane shows a non-homogeneous structure. This is because the control oxidation reaction leads to the fact that the pore structure and the microstructure of the 
material are different between the surface and the interior of the TORC membrane. When fractured in liquid nitrogen, there is a different morphology from the homogeneous RC membrane. Compared with the cross-section morphology of PET-TORC membranes, the cross-section of the PEI-TORC membrane became flat, suggesting that the uniformity of the membrane structure was improved due to the crosslinking reaction; however, the pore size and shape of the middle part of the membrane are different from those of the peripheral part, suggesting both oxidation and crosslinking reaction affected the morphology and structure of the PEI-TORC membranes. Moreover, this structural feature makes it unsuitable as a molecular sieve.
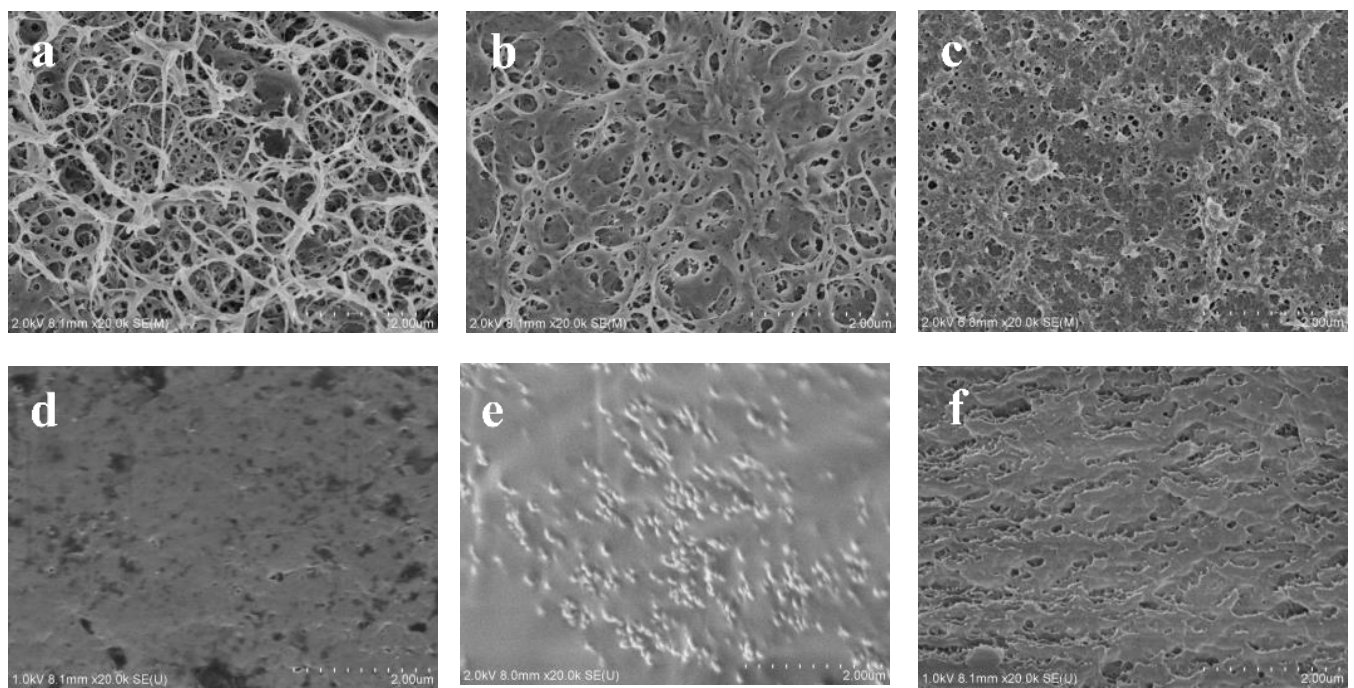

Figure 2. SEM images of the RC membrane: (a) surface, (d) cross-section; TORC membrane: (b) surface,

(e) cross-section; PEI-TORC membrane: (c) surface, (f) cross-section.

As shown in Figure 3, the mechanical properties of the modified membranes were reduced. The tensile strength and elongation at break of RC membranes were $81.9 \mathrm{MPa}$, and $9.0 \%$, respectively, while the tensile strength and elongation at break of PEI-TORC membranes were $31.0 \mathrm{MPa}$ and $2.7 \%$, respectively. The decrease of the mechanical properties of TORC membranes was due to the oxidative degradation of cellulose and the non-uniformity of the membrane materials caused by the control of the oxidation reaction. The decrease in elongation at break of the PEI-TORC membranes was due to the fact that the crosslinking reaction limits the movement of the molecular chain, and the descent in the tensile strength is likely due to the inhomogeneity of the material.

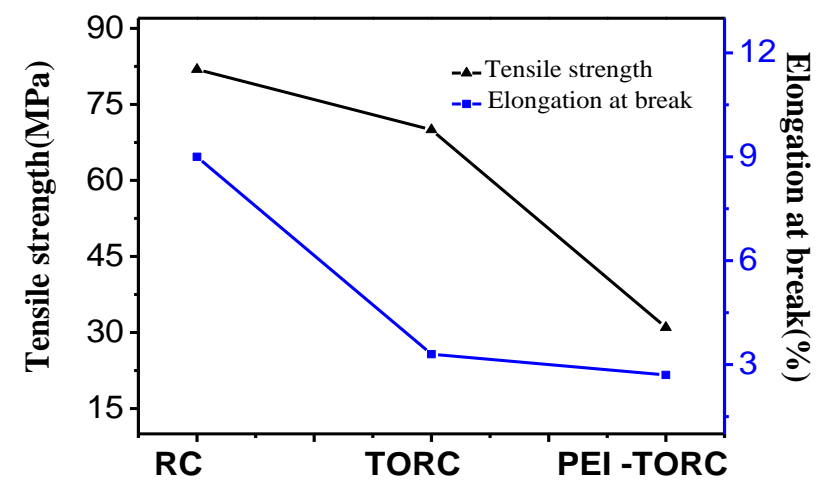

Figure 3. Tensile strength and elongation at break of RC, TORC and PEI-TORC membranes. 
In order to explore the potential application value of membrane in water treatment, the structure and performance of the PEI-TORC membrane were further studied. The porosity, water flux and pore size of the PEI-TORC membrane were $72 \%, 6.14 \mathrm{~L} \cdot \mathrm{m}^{-2} \cdot \mathrm{h}^{-1} \cdot \mathrm{bar}^{-1}$ and $25.9 \mathrm{~nm}$ (the mean pore size), respectively. Importantly, it is possible to adjust the morphology, structure and properties of the PEI-TORC membrane by changing the various influencing factors in the preparation process, making it possible to further expand the application range of the modified cellulose membrane.

\subsection{Adsorption Properties of the RC and PEI-TORC Membranes}

The dye removal percentages of the RC and PEI-TORC membranes are also shown in Figure 4. RC membranes exhibited a poor adsorption capacity, meaning that raw cellulose did not have enough binding sites for dye adsorption. However, the adsorption capacity of hydroxyl for the removal of positively-charged dyes, the hydroxyl groups on the surface, is quite limited because most of them are included in the intra- and inter-molecule hydrogen-bond network. The removal efficiency of the PEI-TORC membrane was significantly higher than that of the RC material. The sorption of dyes onto adsorbents may well include chemical sorption, which could greatly improve the adsorption capacity. From the change in the FTIR of the functions in PEI-TORC upon the adsorption of MB or XO, it is apparent that the adsorption process is likely to involve chemical sorption.

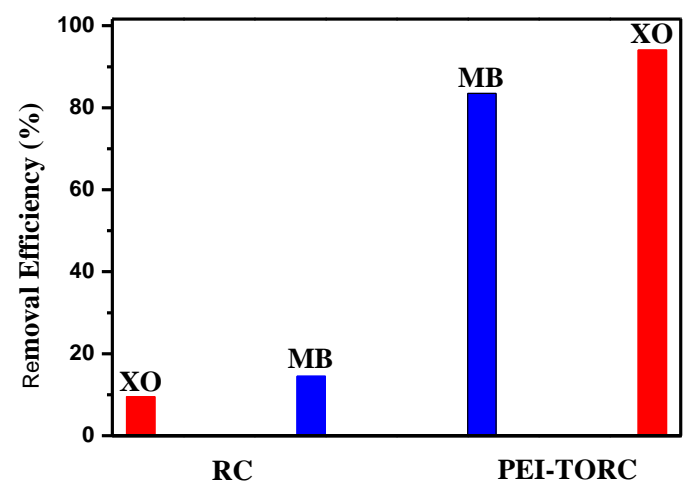

Figure 4. The removal efficiencies of RC and PEI-TORC (initial dye concentration: $30 \mathrm{mg} \cdot \mathrm{L}^{-1}, 60 \mathrm{~mL}$ $\mathrm{MB}$ or $\mathrm{XO}$ solution, $70 \mathrm{mg}$ adsorbent, $100 \mathrm{~min}, \mathrm{pH}=6.8$ ).

\subsection{Effect of the $\mathrm{pH}$ on Adsorption}

The solution $\mathrm{pH}$ significantly alters the level of electrostatic or molecular interaction between the adsorbent and the adsorbate due to the charge distribution on the material [11]. Thus, the $\mathrm{pH}$ of the solution is one of the determinants of the efficiency of the adsorbent for dye removal, as shown in Figure 5. The zeta potentials of PEI-TORC at various $\mathrm{pH}$ are also shown in Figure 5. The results showed that PEI-TORC exhibited a positively-charged surface at a $\mathrm{pH}$ lower than 5.7, while a negatively-charged surface at a $\mathrm{pH}$ higher than 5.7, which is shown to be electrically neutral (i.e., zero point charge). Xylenol orange is a negatively-charged species [35], while the methylene blue molecules are positively charged [36]. PEI-TORC exhibited positive surface charge at a $\mathrm{pH}$ lower than 5.7, leading to electrostatic attraction between the bioadsorbent and the anionic group of $\mathrm{XO}$, resulting in maximum removal efficiency of $95.7 \%$ at $\mathrm{pH} 4.1$. However, the PEI-TORC exhibited a negatively-charged surface, resulting in weaker electrostatic interactions between the bioadsorbent and $\mathrm{XO}$ and lower dye adsorption [37], with increasing the $\mathrm{pH}$ to higher than 5.7. The efficiency of the bioadsorbent for $\mathrm{MB}$ dye removal kept increasing in the $\mathrm{pH}$ range of 4.1-10.9, indicating the electronegativity of PEI-TORC continued to increase with increasing $\mathrm{pH}$ values. The results revealed the excellent dye removal efficiency of the bioadsorbent for both anionic and cationic dyes. The high adsorption of cationic or acidic dyes at higher $\mathrm{pH}$ may be due to the unique molecular structure of this 
bioadsorbent. However, considering the practical application and the zeta potential of the adsorbent, this paper mainly studied the adsorption performance of the bioadsorbent at $\mathrm{pH} 4.6$ and 6.8.

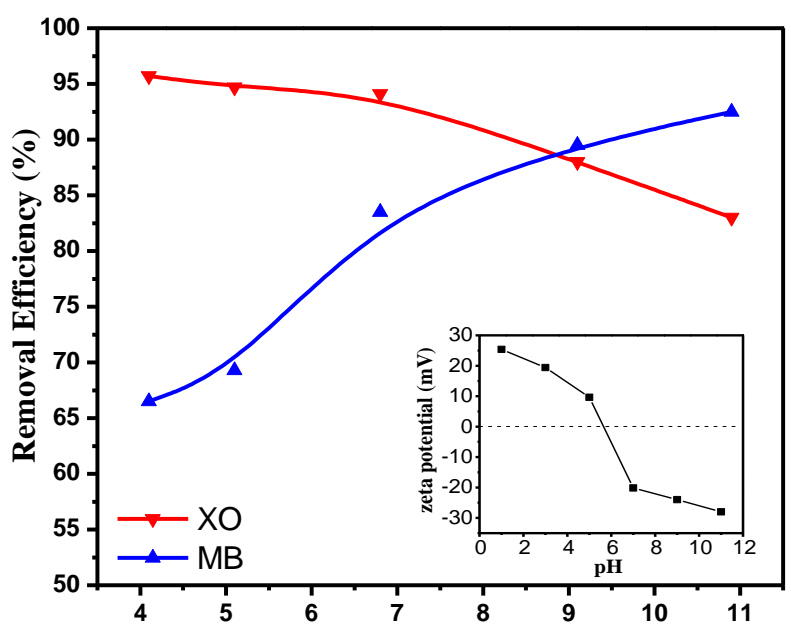

Figure 5. Effect of $\mathrm{pH}$ on the dye removal efficiencies of $\mathrm{XO}$ and $\mathrm{MB}$ (initial dye concentration: $200 \mathrm{mg} \cdot \mathrm{L}^{-1}, 30 \mathrm{~mL}$ dye solution, $70 \mathrm{mg}$ adsorbent).

\subsection{Effect of the Initial Dye Concentration and the Adsorption Isotherm}

As shown in Figure 6a, the dye adsorption capacity of PEI-TORC increased with the increase of the initial concentration and then tended to level off, resulting from the increasing driving force from the concentration gradient [38]. However, the equilibrium adsorption capacity and the adsorption behavior of PET-TORC varied greatly due to different types of dyes and different $\mathrm{pH}$ values. The adsorption capacity of $\mathrm{XO}$ was higher than that of $\mathrm{MB}$, which was attributed to the limited number of carboxyl groups on the surface of the bioadsorbent, caused by controlled oxidation. The maximum adsorption capacities of $\mathrm{XO}$ and $\mathrm{MB}$ reached 403 and $74 \mathrm{mg} \cdot \mathrm{g}^{-1}$, at $\mathrm{pH} 4.6$, respectively; while the maximum values of $\mathrm{XO}$ and $\mathrm{MB}$ reached 229 and $139 \mathrm{mg} \cdot \mathrm{g}^{-1}$, at $\mathrm{pH} 6.8$, respectively.

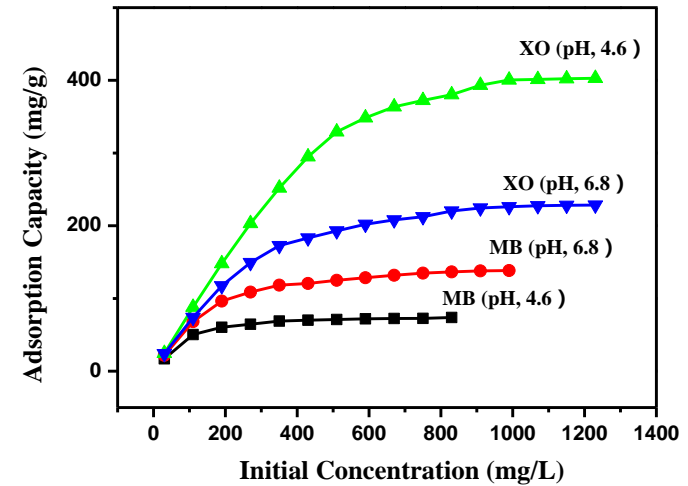

(a)

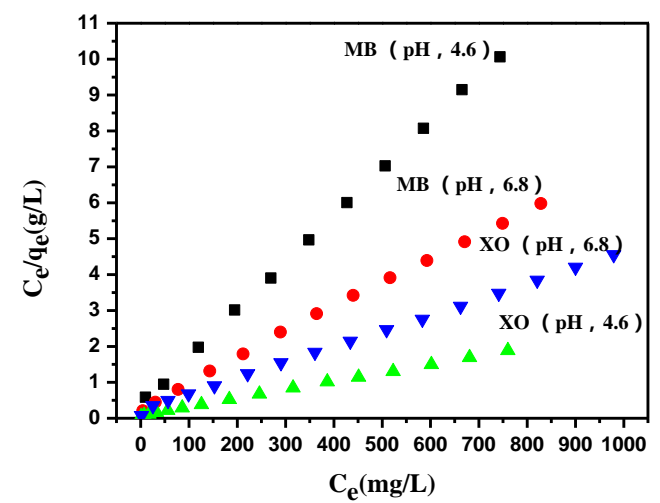

(b)

Figure 6. (a) Effect of initial concentration on dye adsorption by PEI-TORC membranes; (b) the plots of $C_{\mathrm{e}} / q_{\mathrm{e}}$ against $C_{\mathrm{e}}$ for adsorption of $\mathrm{XO}$ and $\mathrm{MB}$ at different $\mathrm{pH}$.

The adsorption isotherm study was carried out on two well-known isotherms, Langmuir and Freundlich. When $C_{\mathrm{e}} / q_{\mathrm{e}}$ was plotted against $C_{\mathrm{e}}$, a straight line with slope $1 / q_{\max }$ was obtained (Figure $6 \mathrm{~b}$ ), indicating that the adsorption of the both dyes onto PEI-TORC follows the Langmuir isotherm. The $q_{\max }$ values of the Langmuir model for adsorption of MB were $77 \mathrm{mg} \cdot \mathrm{g}^{-1}(\mathrm{pH}, 4.6)$ and $144 \mathrm{mg} \cdot \mathrm{g}^{-1}(\mathrm{pH}, 6.8)$, while the $q_{\max }$ values for adsorption of $\mathrm{XO}$ were $420 \mathrm{mg} \cdot \mathrm{g}^{-1}(\mathrm{pH}, 4.6)$ and 
$241 \mathrm{mg} \cdot \mathrm{g}^{-1}(\mathrm{pH}, 6.8)$, which was similar to the experimental $q_{\max }$ values obtained from Figure 6a. Thus, these results indicated that the PEI-TORC membrane exhibited relatively high effectiveness in removing the tested dyes, especially anionic dyes. Moreover, the isotherm parameters are summarized in Table 2. It is evident that the Langmuir isotherm model fits the experimental data better than the Freundlich model.

Table 2. Isotherm parameters for the adsorption of XO and MB onto PEI-TORC.

\begin{tabular}{|c|c|c|c|c|c|c|c|}
\hline \multirow[b]{2}{*}{$\mathrm{pH}$} & \multicolumn{4}{|c|}{ Langmuir Model } & \multicolumn{3}{|c|}{ Freundlich Model } \\
\hline & Dyes & $\begin{array}{c}K_{1} \\
\left(\mathrm{~L} \cdot \mathrm{mg}^{-1}\right)\end{array}$ & $\underset{\left(\mathrm{mg} \cdot \mathrm{g}^{-1}\right)}{q_{\max }}$ & $R^{2}$ & $n$ & $\begin{array}{c}K_{\mathrm{f}} \\
\left(\mathrm{mg} \cdot \mathrm{g}^{-1}\right)\end{array}$ & $R^{2}$ \\
\hline \multirow{2}{*}{6.8} & $\mathrm{XO}$ & 0.018 & 240.96 & 0.9981 & 2.89 & 25.28 & 0.9465 \\
\hline & MB & 0.024 & 144.09 & 0.9987 & 3.12 & 18.64 & 0.8902 \\
\hline \multirow{2}{*}{4.6} & $\mathrm{XO}$ & 0.030 & 420.17 & 0.9995 & 2.56 & 39.30 & 0.8922 \\
\hline & MB & 0.031 & 76.57 & 0.9998 & 3.36 & 11.90 & 0.8170 \\
\hline
\end{tabular}

\subsection{Effect of the Contact Time and the Adsorption Kinetics}

Figure 7 shows the dye removal efficiency and color change of $\mathrm{XO}$ and $\mathrm{MB}$ as a function of the adsorption time. The percentage of dye removal increased rapidly within the first $40 \mathrm{~min}$, and the absorption equilibrium was reached at ca. $100 \mathrm{~min}$. Furthermore, the color of the $\mathrm{XO}$ and MB solutions gradually became lighter with the adsorption time. The color of the $\mathrm{XO}$ solution completely disappeared after the adsorption process. Accordingly, the PEI-TORC membrane shifted from dark red to orange after adsorption, in line with the dye removal efficiency results. In the adsorption stage, the large number of hydrophilic hydroxyl, carboxyl and amino groups on the surface of the adsorbent resulted in electrostatic interactions that occurred upon rapid migration of the anionic $\mathrm{XO}$ or cationic $\mathrm{MB}$ dyes to the surface adsorption sites (i.e., $-\mathrm{COOH}$ and $-\mathrm{NH}_{2}$ ) on the bioadsorbent, and the number of dye molecules adsorbed on the membrane increased with the adsorption time and levelled off at $50 \mathrm{~min}$ as a result of electrostatic repulsion forces between the adsorbed dye molecules. Therefore, the optimum contact time for the adsorption of $\mathrm{XO}$ and $\mathrm{MB}$ was ca. 50 min (i.e., $93 \%$ of $\mathrm{XO}$ and $83 \%$ of $\mathrm{MB}$ were removed). These results demonstrated that the PEI-TORC membrane is a good adsorbent for the rapid removal of $\mathrm{XO}$ and $\mathrm{MB}$ from waste waters.

As shown in Table 3, the $R^{2}$ values for MB and XO indicated that pseudo-second order (PSO) kinetic models could be used to predict the behavior over the whole range of the adsorption process, which indicating that the intraparticle diffusion was involved in the adsorption process. At a $\mathrm{pH}$ of 6.8, the $q_{\mathrm{e}}$ values for XO and MB calculated with a pseudo-second order model were 25 and $22 \mathrm{mg} \cdot \mathrm{g}^{-1}$, respectively, and these values changed to $25 \mathrm{and} 18 \mathrm{mg} \cdot \mathrm{g}^{-1}$ at a $\mathrm{pH}$ of 4.6. These results were in good agreement with the experimental data.
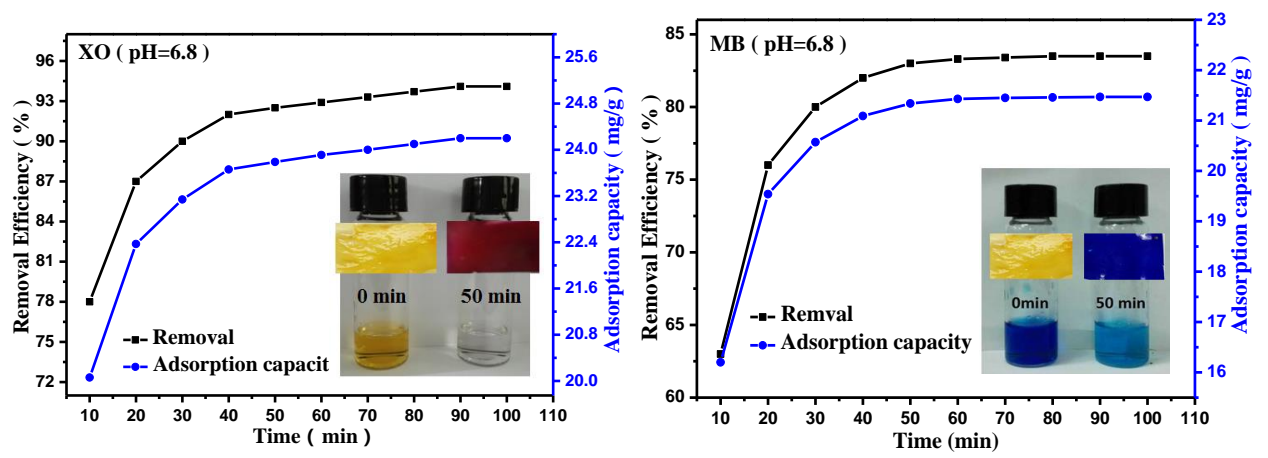

Figure 7. Cont. 

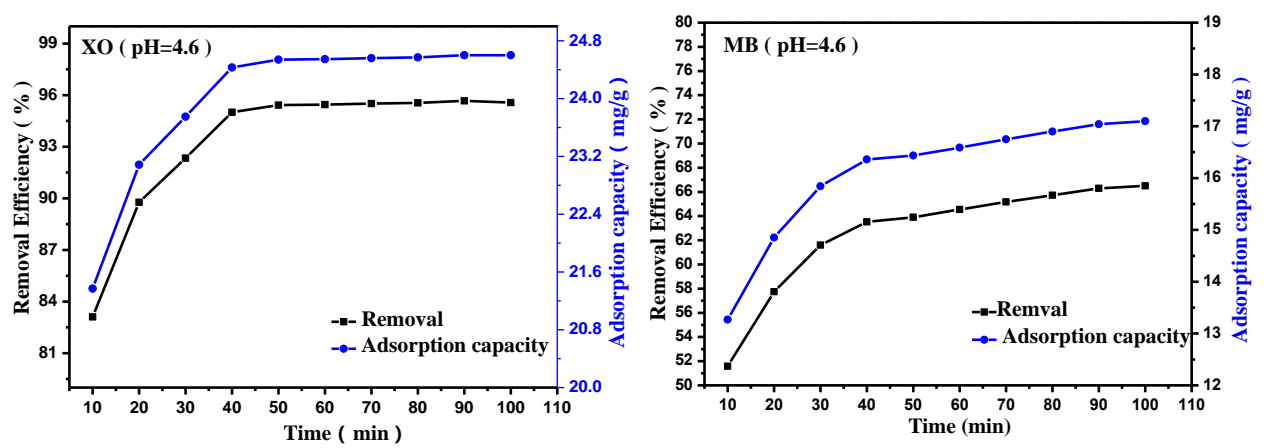

Figure 7. Effect of contact time on the dye removal efficiencies of $\mathrm{XO}$ and $\mathrm{MB}$ (initial dye concentration: $30 \mathrm{mg} \mathrm{L}^{-1}, 60 \mathrm{~mL} \mathrm{MB}$ or XO solution, $70 \mathrm{mg}$ adsorbent, $10-100 \mathrm{~min}, \mathrm{pH}=6.8$ or 4.6).

Table 3. Kinetic parameters for the adsorption of $\mathrm{XO}$ and $\mathrm{MB}$ onto PEI-TORC.

\begin{tabular}{|c|c|c|c|c|c|c|c|}
\hline \multirow[b]{2}{*}{$\mathrm{pH}$} & \multicolumn{4}{|c|}{ Pseudo-First Order Model } & \multicolumn{3}{|c|}{ Pseudo-Second Order Model } \\
\hline & Dyes & $\begin{array}{c}K_{1} \\
\left(\mathrm{~g} \cdot \mathrm{mg}^{-1} \min ^{-1}\right)\end{array}$ & $\begin{array}{c}q_{\mathrm{e}} \\
\left(\mathrm{mg} \cdot \mathrm{g}^{-1}\right)\end{array}$ & $R^{2}$ & $\begin{array}{c}K_{2} \\
\left(\mathrm{~g} \cdot \mathrm{mg}^{-1} \cdot \min ^{-1}\right)\end{array}$ & $\begin{array}{c}q_{\mathrm{e}} \\
\left(\mathrm{mg} \cdot \mathrm{g}^{-1}\right)\end{array}$ & $R^{2}$ \\
\hline \multirow{2}{*}{6.8} & $\mathrm{XO}$ & 0.049 & 5.16 & 0.9753 & 0.0092 & 24.75 & 0.9999 \\
\hline & MB & 0.092 & 13.01 & 0.9954 & 0.017 & 22.16 & 0.9996 \\
\hline \multirow{2}{*}{4.6} & $\mathrm{XO}$ & 0.072 & 5.09 & 0.9144 & 0.028 & 25.03 & 0.9999 \\
\hline & $\mathrm{MB}$ & 0.054 & 7.61 & 0.9631 & 0.014 & 17.84 & 0.9997 \\
\hline
\end{tabular}

\subsection{Reusability}

Figure 8 shows the reusability of the PEI-TORC membrane. After three consecutive desorption-adsorption cycles, the dye removal rates towards $\mathrm{XO}$ and $\mathrm{MB}$ decreased by 6 and 11\%, respectively. Therefore, the adsorbent showed high reusability for the removal of $\mathrm{XO}$ and $\mathrm{MB}$.

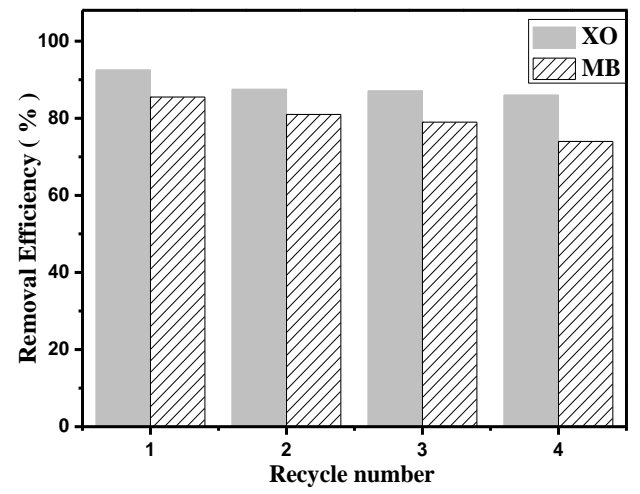

Figure 8. The dye removal efficiency of $\mathrm{XO}$ and $\mathrm{MB}$ after three desorption-adsorption cycles.

\section{Conclusions}

Functional membranes based on regenerated cellulose were prepared by grafting PEI onto controlled oxidized RC membranes. Modification conditions were screened to achieve the biofunctionalization of the regenerated cellulose membranes successfully and to retain the porous membrane structure. The maximum adsorption capacities of cationic and anionic dyes was observed, being the highest for xylenol orange $\left(403 \mathrm{mg} \cdot \mathrm{g}^{-1}\right)$, followed by methylene blue $\left(139 \mathrm{mg} \cdot \mathrm{g}^{-1}\right)$. Furthermore, the membranes showed low flux, supporting the usefulness of them as adsorbents. One may adjust the morphology, structure and properties of the PEI-TORC membrane by changing the various influencing factors in the preparation process, for exploring its potential application in the future. 
Acknowledgments: Financial support from MOE\&SAFEA for the 111 Project (B13025) is gratefully acknowledged.

Author Contributions: Wei Wang, Qian Bai, Huiyu Bai and Xiaoya Liu conceived of and designed the experiments. Wei Wang and Qian Bai performed the experiments and analyzed the data. Wei Wang, Qian Bai and Tao Liang wrote the paper. All authors discussed the results and improved the final text of the paper.

Conflicts of Interest: The authors declare no conflict of interest.

\section{References}

1. Sokolowska-Gajda, J.; Freeman, H.S.; Reife, A. Synthetic dyes based on environmental considerations. Part 2: Iron complexes formazan dyes. Dyes Pigment. 1996, 30, 1-20. [CrossRef]

2. Fleischmann, C.; Lievenbrück, M.; Ritter, H. Polymers and Dyes: Developments and Applications. Polymers 2015, 7, 717-746. [CrossRef]

3. Karadağ, E.; Saraydin, D.; Güven, O. Removal of some cationic dyes from aqueous solutions by acrylamide/itaconic acid hydrogels. Water Air Soil Pollut. 1998, 106, 369-378. [CrossRef]

4. Sharma, P.; Kaur, H.; Sharm, M.; Sahore, V. A review on applicability of naturally available adsorbents for the removal of hazardous dyes from aqueous waste. Environ. Monit. Assess. 2011, 183, 151-195. [CrossRef] [PubMed]

5. Liu, L.L.; Yu, C.X.; Zhou, W.; Zhang, Q.G.; Liu, S.M.; Shi, Y.F. Construction of Four Zn(II) Coordination Polymers Used as Catalysts for the Photodegradation of Organic Dyes in Water. Polymers 2016, 8, 3. [CrossRef]

6. Guendouz, S.; Khellaf, N.; Zerdaoui, M.; Ouchefoun, M. Biosorption of synthetic dyes (direct red 89 and reactive green 12) as an ecological refining step in textile effluent treatment. Environ. Sci. Pollut. Res. 2013, 20, 3822-3829. [CrossRef] [PubMed]

7. Ganesan, P.; Kamaraj, R.; Sozhan, G.; Vasudevan, S. Oxidized multiwalled carbon nanotubes as adsorbent for the removal of manganese from aqueous solution. Environ. Sci. Pollut. Res. 2013, 20, 987-996. [CrossRef] [PubMed]

8. Sanghi, R.; Bhattacharya, B. Review on decolorisation of aqueous dye solutions by low cost adsorbents. Color Technol. 2002, 118, 256-269. [CrossRef]

9. Kyzas, G.; Kostoglou, M. Green Adsorbents for Wastewaters: A Critical Review. Materials 2014, 7, $333-364$. [CrossRef] [PubMed]

10. Zhou, Y.; Zhang, M.; Hu, X.; Wang, X.; Niu, J.; Ma, T. Adsorption of Cationic Dyes on a Cellulose-Based Multicarboxyl Adsorbent. J. Chem. Eng. Data 2013, 58, 413-421. [CrossRef]

11. Jin, L.; Li, W.; Xu, Q. Amino-functionalized nanocrystalline cellulose as an adsorbent for anionic dyes. Cellulose 2015, 22, 2443-2456. [CrossRef]

12. Qiao, H.; Zhou, Y.; Yu, F.; Wang, E.; Min, Y.; Huang, Q.; Pang, L.; Ma, T. Effective removal of cationic dyes using carboxylate-functionalized cellulose nanocrystals. Chemosphere 2015, 141, 297-303. [CrossRef] [PubMed]

13. Qi, Y.; Li, J.; Wang, L. Removal of Remazol Turquoise Blue G-133 from aqueous medium using functionalized cellulose from recycled newspaper fiber. Ind. Crop. Prod. 2013, 50, 15-22. [CrossRef]

14. Luo, X.G.; Zhang, L. High effective adsorption of organic dyes on magnetic cellulose beads entrapping activated carbon. J. Hazard. Mater. 2009, 171, 340-347. [CrossRef] [PubMed]

15. Shiralipour, R.; Larki, A. Pre-concentration and determination of tartrazine dye from aqueous solutions using modified cellulose nanosponges. Ecotoxicol. Environ. Saf. 2017, 135, 123-129. [CrossRef] [PubMed]

16. Zhu, W.; Liu, L.; Liao, Q.; Chen, X.; Qian, Z.; Shen, J.; Liang, J.; Yao, J. Functionalization of cellulose with hyperbranched polyethylenimine for selective dye adsorption and separation. Cellulose 2016, 23, 3785-3797. [CrossRef]

17. Ma, H.; Burger, C.; Hsiao, B.S.; Chu, B. Nanofibrous microfiltration membrane based on cellulose nanowhiskers. Biomacromolecules 2012, 13, 180-186. [CrossRef] [PubMed]

18. Karim, Z.; Mathew, A.P.; Grahn, M.; Mouzon, J.; Oksman, K. Nanoporous membranes with cellulose nanocrystals as functional entity in chitosan: removal of dyes from water. Carbohydr. Polym. 2014, 112, 668-676. [CrossRef] [PubMed] 
19. Gopakumar, D.A.; Pasquini, D.; Henrique, M.A.; Morais, L.C.; Grohens, Y.; Thomas, S. Meldrum's Acid Modified Cellulose Nanofiber-Based Polyvinylidene Fluoride Microfiltration Membrane for Dye Water Treatment and Nanoparticle Removal. ACS Sustain. Chem. Eng. 2017, 5, 2026-2033. [CrossRef]

20. Wang, K.; Ma, Q.; Wang, S.D.; Liu, H.; Zhang, S.Z.; Bao, W.; Zhang, R.Q.; Ling, L.Z. Electrospinning of silver nanoparticles loaded highly porous cellulose acetate nanofibrous membrane for treatment of dye wastewater. Appl. Phys. A 2016, 122, 40. [CrossRef]

21. Carpenter, A.W.; Lannoy, C.F.; Wiesner, M.R. Cellulose nanomaterials in water treatment technologies. Environ. Sci. Technol. 2015, 49, 5277-5287. [CrossRef] [PubMed]

22. He, S.; Fang, H.; Xu, X. Filtering absorption and visual detection of methylene blue by nitrated cellulose acetate membrane. Korean J. Chem. Eng. 2016, 33, 1472-1479. [CrossRef]

23. Oshima, T.; Kondo, K.; Ohto, K.; Inoue, K.; Baba, Y. Preparation of phosphorylated bacterial cellulose as an adsorbent for metal ions. React. Funct. Polym. 2008, 68, 376-383. [CrossRef]

24. Ma, X.J.; Cao, S.L.; Lin, L. Hydrothermal pretreatment of bamboo and cellulose degradation. Bioresour. Technol. 2013, 148, 408-413. [CrossRef] [PubMed]

25. Fitz-Binder, C.; Bechtold, T. One-sided surface modification of cellulose fabric by printing a modified TEMPO-mediated oxidant. Carbohydr. Polym. 2014, 106, 142-147. [CrossRef] [PubMed]

26. Sun, X.F.; Wang, S.G.; Cheng, W.; Fan, M.; Tian, B.H.; Gao, B.Y.; Li, X.M. Enhancement of acidic dye biosorption capacity on poly(ethylenimine) grafted anaerobic granular sludge. J. Hazard. Mater. 2011, 189, 27-33. [CrossRef] [PubMed]

27. Zhang, L.; Mao, Y.; Zhou, J.; Cai, J. Effects of Coagulation Conditions on the Properties of Regenerated Cellulose Films Prepared in NaOH/Urea Aqueous Solution. Ind. Eng. Chem. Res. 2005, 44, $522-529$. [CrossRef]

28. Cai, J.; Wang, L.X.; Zhang, L.N. Influence of coagulation temperature on pore size and properties of cellulose membranes prepared from $\mathrm{NaOH}$-urea aqueous solution. Cellulose 2007, 14, 205-215. [CrossRef]

29. Mohamed, M.A.; Salleh, W.N.W.; Jaafar, J.; Ismail, A.F.; Mutalib, M.A.; Jamil, S.M. Feasibility of recycled newspaper as cellulose source for regenerated cellulose membrane fabrication. J. Appl. Polym. Sci. 2015, 132, 43. [CrossRef]

30. Lai, C.; Guo, X.; Xiong, Z. A comprehensive investigation on adsorption of Ca (II), Cr (III) and Mg (II) ions by 3D porous nickel films. J. Colloid Interface Sci. 2016, 463, 154-163. [CrossRef] [PubMed]

31. Yu, X.; Tong, S.; Ge, M. Synthesis and characterization of multi-amino-functionalized cellulose for arsenic adsorption. Carbohydr. Polym. 2013, 92, 380-387. [CrossRef] [PubMed]

32. Montanari, S.; Roumani, M.; Heux, L.; Vignon, M.R. Topochemistry of Carboxylated Cellulose Nanocrystals Resulting from TEMPO-Mediated Oxidation. Macromolecules 2005, 38, 1665-1671. [CrossRef]

33. Han, K.N.; Yu, B.Y.; Kwak, S.Y. Hyperbranched poly (amidoamine)/polysulfone composite membranes for Cd (II) removal from water. J. Membr. Sci. 2012, 396, 83-91. [CrossRef]

34. Sehaqui, H.; Larraya, U.P.D.; Liu, P.; Pfenninger, N.; Mathew, A.P. Enhancing adsorption of heavy metal ions onto biobased nanofibers from waste pulp residues for application in wastewater treatment. Cellulose 2014, 21, 2831-2844. [CrossRef]

35. Khan, M.N.; Bhutto, S. Kinetic study of the oxidatwe decolorization of xylenol orange by hydrogen peroxide in micellar medium. JCCS 2010, 55, 170-175.

36. Zhang, W.; Zhou, C.; Zhou, W.; Lei, A.; Zhang, Q.; Wan, Q.; Zou, B. Fast and Considerable Adsorption of Methylene Blue Dye onto Graphene Oxide. Bull. Environ. Contam. Toxicol. 2011, 87, 86-90. [CrossRef] [PubMed]

37. Chen, C.; Zhang, M.; Guan, Q. Kinetic and thermodynamic studies on the adsorption of xylenol orange onto MIL-101 (Cr). Chem. Eng. J. 2012, 183, 60-67. [CrossRef]

38. Min, L.U.; Zhang, Y.; Guan, X. Thermodynamics and kinetics of adsorption for heavy metal ions from aqueous solutions onto surface amino-bacterial cellulose. Trans. Nonferrous Met. Soc. 2014, 24, 1912-1917.

(C) 2017 by the authors. Licensee MDPI, Basel, Switzerland. This article is an open access article distributed under the terms and conditions of the Creative Commons Attribution (CC BY) license (http:/ / creativecommons.org/licenses/by/4.0/). 